\title{
COVID-19 presenting with agraphia and conduction aphasia in a patient with left-hemisphere ischemic stroke
}

\author{
Konstantinos Priftis ${ }^{1,2}\left(\mathbb{D} \cdot\right.$ Lorella Algeri $^{3} \cdot$ Stella Villella ${ }^{4} \cdot$ Maria Simonetta Spada $^{3}$ \\ Received: 21 August 2020 / Accepted: 24 September 2020 / Published online: 28 September 2020 \\ (C) Fondazione Società Italiana di Neurologia 2020
}

\begin{abstract}
COVID-19 following infection by SARS-CoV-2 can affect the brain causing confusion, depression, and dementia-like signs. Nonetheless, the presence of more specific neuropsychological signs because of COVID-19 remains unexplored. We report on LA, a patient who was affected by a left-hemisphere ischemic stroke, probably because of SARS-CoV-2. The patient showed a highly specific neuropsychological profile characterized by severe agraphia and some signs of conduction aphasia. All other cognitive and sensorimotor functions remained intact. We sustain that specific neuropsychological signs can be observed in patients with COVID-19. Therefore, in-depth and comprehensive neuropsychological assessment should be included to better explore and qualify the neuropsychological consequences of COVID-19. This is a new challenge for diagnosis and rehabilitation, with important consequences for the involved neuropsychological services.
\end{abstract}

Keywords COVID-19 $\cdot$ SARS-CoV-2 $\cdot$ Conduction aphasia $\cdot$ Agraphia

\section{Introduction}

Severe acute respiratory syndrome coronavirus 2 (SARSCoV-2), resulting in corona virus disease 2019 (COVID-19), has caused a pandemic. Indeed, more than 950,000 deaths have been reported world-wide (https://covid19.who.int/). Although COVID-19 is mainly characterized by severe pulmonary signs, there is now growing evidence that the brain can be also affected $[1,2]$. Indeed, neurological disorders have been reported in patients with COVID-19. These disorders include brain inflammation, hyposmia/hypogeusia, GuillainBarré syndrome, and stroke [1,2]. Confusion, agitation, dementia-like signs, and psychotic signs following COVID-

Konstantinos Priftis

konstantinos.priftis@unipd.it

1 Department of General Psychology, University of Padua, Padua, Italy

2 Human Inspired Technology Center, University of Padua, Padua, Italy

3 UOC Psychology, Papa Giovanni XXIII Hospital, Bergamo, Italy

4 UOC Special Rehabilitation, Papa Giovanni XXIII Hospital, Bergamo, Italy
19 have been also described [1, 2]. Furthermore, Helms et al. [3] have reported the presence of dysexecutive syndromes in 14 out of 39 patients affected by COVID-19. Nevertheless, the presence of more focal neuropsychological disorders (e.g. aphasia, agraphia, alexia, agnosia, and neglect), following SARS-CoV-2, remains a largely unexplored issue. Therefore, in the present study, we aimed to investigate, more in depth, the specific and focal neuropsychological consequences of SARS-CoV-2, in a patient affected by lefthemisphere stroke.

\section{Case report}

The study was conducted according to the principles of the Declaration of Helsinki. The patient gave his informed consent to participate. LA was a 53-year-old, right-handed male, with 8 years of education. On April 6, 2020, after 2 weeks of fever, the patient was admitted to an emergency room with signs of aphasia and behavioural agitation. A chest X-ray scan revealed the presence of mild interstitial pulmonary signs. Serological tests (IcG Ab) confirmed the presence of antibodies for SARS-CoV2. FLAIR-MRI imaging revealed the presence of hyperintense signal in the temporo-parieto-insular regions of the left hemisphere extending subcortically to the homolateral semioval centres (Fig. 1). This signal was compatible with an ischemic stroke 


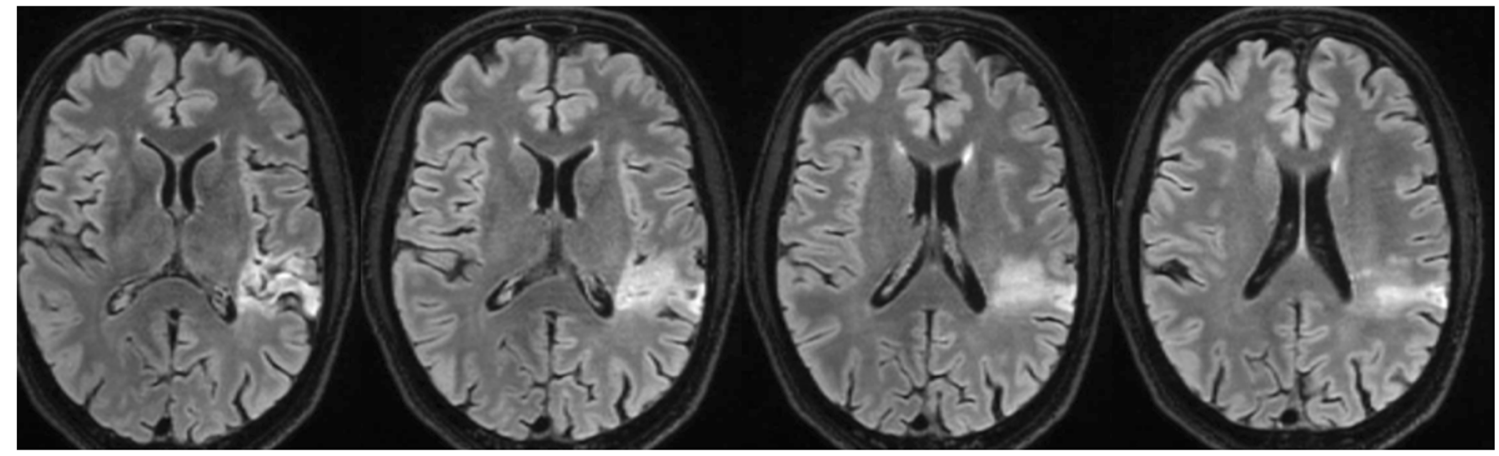

Fig. 1 FLAIR-MRI scan of LA's brain, showing hyperintense signal in the left temporo-parieto-insular region, extending to the homolateral semioval center

Table 1 Language, number processing and calculation [4]

\begin{tabular}{|c|c|c|c|c|}
\hline & Range & Corrected score & Cut-off & Diagnosis \\
\hline \multicolumn{5}{|l|}{-Oral repetition } \\
\hline -Words & $0-10$ & 10 & 8.8 & Normal \\
\hline -Non-words & $0-5$ & 3.8 & 2.0 & Normal \\
\hline -Sentences & $0-3$ & 1 & 3.0 & Abnormal \\
\hline \multicolumn{5}{|l|}{-Reading aloud } \\
\hline -Words & $0-10$ & 10 & 6.4 & Normal \\
\hline -Non-words & $0-5$ & 5 & 4.0 & Normal \\
\hline -Sentences & $0-2$ & 2 & 1.3 & Normal \\
\hline \multicolumn{5}{|l|}{-Writing to dictation } \\
\hline -Words & $0-10$ & 5.9 & 6.3 & Abnormal \\
\hline -Non-words & $0-5$ & 0.6 & 1.4 & Abnormal \\
\hline -Sentences & $0-2$ & 0 & 0.6 & Abnormal \\
\hline \multicolumn{5}{|l|}{-Naming } \\
\hline \multicolumn{5}{|l|}{-Nouns } \\
\hline -Oral naming & $0-10$ & 10 & 8.2 & Normal \\
\hline -Written naming & $0-5$ & 2.9 & 2.7 & Normal \\
\hline \multicolumn{5}{|l|}{-Verbs } \\
\hline -Oral naming & $0-10$ & 8.9 & 6.1 & Normal \\
\hline -Written naming & $0-5$ & 3,8 & 3.0 & Normal \\
\hline \multicolumn{5}{|l|}{-Colors } \\
\hline -Spoken naming & $0-5$ & 5 & 4.0 & Normal \\
\hline \multicolumn{5}{|l|}{-Comprehension } \\
\hline \multicolumn{5}{|l|}{-Single words } \\
\hline -Oral comprehension & $0-20$ & 20 & 18.4 & Normal \\
\hline -Written comprehension & $0-20$ & 18.9 & 17.0 & Normal \\
\hline \multicolumn{5}{|l|}{-Sentences } \\
\hline -Oral comprehension & $0-14$ & 14 & 11.6 & Normal \\
\hline -Written comprehension & $0-14$ & 14 & 11.3 & Normal \\
\hline \multicolumn{5}{|l|}{-Number processing } \\
\hline -Repetition & $0-10$ & 10 & 8.8 & Normal \\
\hline -Reading aloud & $0-10$ & 8.3 & 7.6 & Normal \\
\hline -Writing & $0-8$ & 8 & 6.3 & Normal \\
\hline -Transcoding number words to Arabic digits & $0-8$ & 8 & 4.2 & Normal \\
\hline \multicolumn{5}{|l|}{-Calculations } \\
\hline -Additions & $0-3$ & 3 & 2.2 & Normal \\
\hline -Subtractions & $0-3$ & 1 & 1.0 & Normal \\
\hline -Multiplications & $0-4$ & 2.4 & 1.4 & Normal \\
\hline \multicolumn{5}{|l|}{-Verbal fluency } \\
\hline$-\mathrm{F}$ & $0-\infty$ & 6.9 & 5.7 & Normal \\
\hline$-A$ & $0-\infty$ & 2.9 & 4.8 & Abnormal \\
\hline$-\mathrm{S}$ & $0-\infty$ & 5.9 & 5.8 & Normal \\
\hline -Animals & $0-\infty$ & 18.8 & 10.3 & Normal \\
\hline -Objects & $0-\infty$ & 14.7 & 8.5 & Normal \\
\hline -Nouns & $0-\infty$ & 17 & 7.0 & Normal \\
\hline -Verbs & $0-\infty$ & 10.2 & 5.7 & Normal \\
\hline
\end{tabular}


Table 2 Praxis and Token test [5]

\begin{tabular}{lllllll}
\hline & Range & $\begin{array}{l}\text { Raw } \\
\text { score }\end{array}$ & $\begin{array}{l}\text { Corrected } \\
\text { score }\end{array}$ & $\begin{array}{l}\text { Equivalent } \\
\text { score }\end{array}$ & Cut-off & Diagnosis \\
\hline $\begin{array}{c}\text { Praxis } \\
\text { Ideomotor apraxia } \\
\quad(\text { left upper limb) }\end{array}$ & $0-20$ & 20 & 20 & 4 & 0 & Normal \\
$\begin{array}{c}\text { Ideomotor apraxia } \\
\text { (right upper limb) } \\
\text { Constructional apraxia }\end{array}$ & $0-20$ & 20 & 20 & 4 & 0 & Normal \\
Comprehension & $0-14$ & 14 & 14 & 4 & 0 & Normal \\
Token Test & $0-36$ & 34.5 & 33.5 & 4 & 0 & Normal \\
\hline
\end{tabular}

of the middle cerebral artery probably because of thrombophilic processes, probably elicited by SARS-CoV-2. The signal, indeed, appeared discontinuous, and it was characterized by thromboembolic elements distributed in different divisions of the middle cerebral artery (M3, M4). Finally, the midline brain structures were normally aligned and there was no evidence of hemorrhagic conversion.

LA was admitted to our neurorehabilitation unit to receive comprehensive neuropsychological assessment concerning his left-hemisphere syndrome. His previous medical history was unremarkable, except for a visual deficit in the left eye. Neurological examination did not reveal sensory or motor deficits, but LA had a fluctuating sense of temperature in his right hemisoma. LA was alert, collaborative, and aware of his linguistic difficulties. The patient was fully oriented to time, space, and person. Furthermore, he did not show signs of mnestic or executive dysfunction in everyday life.

A comprehensive neuropsychological assessment was then performed (see Tables 1 and 2). LA's praxis was normal: the patient did not show any signs of ideomotor or constructional apraxia. His oral production was fluent, both with reference to spontaneous tasks (i.e. conversation) and to elicited tasks (i.e. picture description; semantic and phonemic verbal fluency, except for phoneme A). Articulatory and prosodic deficits were absent. The syntactic structure of LA's utterances was intact, suggesting the absence of agrammatism. His oral and written comprehension was intact, both for single words and for sentences (see also Token test, Table 2). Number processing and calculation were also intact. Oral and written naming of pictures representing nouns, verbs, and colours was largely spared. Nevertheless, LA produced some phonological paraphasias and he made attempts to self-correction (conduit d'approach).

In contrast, LA showed some signs of conduction aphasia. Although oral repetition of spoken single words and non-words was intact, the patient was severely impaired in orally repeating spoken sentences. Reading aloud words, non-words, and sentences was intact. On the contrary, writing was severely impaired. More precisely, on writing to dictation, the patient produced many paragraphias, which were mainly characterized by the omission or substitution of graphemes. Paragraphias were present for single words, non-words, and sentences.

\section{Discussion}

LA had a largely intact neuropsychological profile, except for the presence of severe agraphia and some signs of conduction aphasia. These deficits were fully compatible with the presence of a temporo-parieto-insular lesion documented by FLAIR MRI. Of course, special caution is required about the pathogenic role of COVID 19 in our case, which is suspected, but cannot be directly demonstrated. LA's stroke, however, might have been elicited by SARS-CoV-2 for three reasons. First, LA was simultaneously affected by thromboembolic events in distinct sites (M3, M4). Second the patient was not affected by risk factors for stroke (e.g. hypertension and diabetes). Finally, LA's medical history was unremarkable.

We suggest that patients affected by SARS-CoV-2 and stroke might not only show diffuse neurocognitive and neurobehavioural signs (e.g. confusion, agitation, psychosis), but they can also present with highly focal neuropsychological disorders, such as agraphia and conduction aphasia. Therefore, in-depth and comprehensive neuropsychological assessment should be performed in these patients to better explore and qualify the neuropsychological consequences of COVID-19. This is a new and important challenge both for neurologists and clinical neuropsychologists involved in the diagnosis and treatment of the consequences of COVID-19.

Acknowledgements We would like to thank LA for his participation to the study. This work was carried out within the scope of the project "useinspired basic research 2", for which the Department of General Psychology of the University of Padova has been recognized as "Department of Excellence" by the Italian Ministry of University and Research.

\section{Compliance with ethical standards}

Ethical approval The study was conducted according to the principles of the Declaration of Helsinki. The patient gave his informed consent to participate. 
Conflict of interest The authors have no conflicts of interest to declare that are relevant to the content of this article.

\section{References}

1. Paterson RW, Brown RL, Benjamin L, Nortley R, Wiethoff S, Bharucha T, Jayaseelan DL, Kumar G, Raftopoulos RE, Zambreanu L, Vivekanandam V, Khoo A, Geraldes R, Chinthapalli K, Boyd E, Tuzlali H, Price G, Christofi G, Morrow J et al (in press) The emerging spectrum of COVID-19 neurology: clinical, radiological and laboratory findings. Brain. https://doi.org/ 10.1093/brain/awaa240

2. Varatharaj A, Thomas N, Ellul MA, Davies NWS, Pollak TA, Tenorio EL, Sultan M, Easton A, Breen G, Zandi M, Coles JP, Manji H, Al-Shahi Salman R, Menon DK, Nicholson TR,
Benjamin LA, Carson A, Smith C, Turner MR et al (in press) Neurological and neuropsychiatric complications of COVID19 in 153 patients: A UK-wide surveillance study. Lancet Psychiatry. https://doi.org/10.1016/S2215-0366(20)30287-X

3. Helms J, Kremer S, Merdji H, Clere-Jehl R, Schenck M, Kummerlen C, Collange O, Boulay C, Fafi-Kremer S, Ohana M, Anheim M, Meziani F (2020) Neurologic features in severe SARS-CoV-2 infection. N Engl J Med 382(23): 2268-2270. https://doi.org/10.1056/NEJMc2008597

4. Capasso R, Miceli G (2001) Esame neuropsicologico per l'afasia. Springer

5. Spinnler H, Tognoni G (1987) Standardizzazione e taratura italiana di test neuropsicologici. Ital J Neurol Sci 6(Suppl. 8):25-27

Publisher's note Springer Nature remains neutral with regard to jurisdictional claims in published maps and institutional affiliations. 